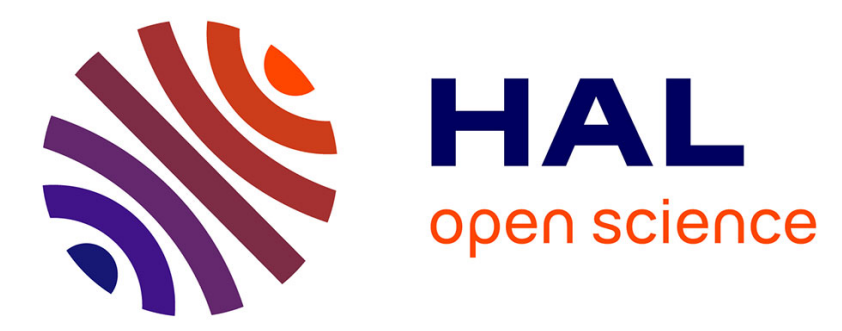

\title{
Wavelengths and temporal effects on the response of mammalian cells to UV radiation: Limitations of action spectra illustrated by genotoxicity \\ Thierry Douki
}

\section{- To cite this version:}

Thierry Douki. Wavelengths and temporal effects on the response of mammalian cells to UV radiation: Limitations of action spectra illustrated by genotoxicity. Journal of Photochemistry and Photobiology B: Biology, 2021, pp.112169. 10.1016/j.jphotobiol.2021.112169 . hal-03155695

\section{HAL Id: hal-03155695 \\ https://hal.science/hal-03155695}

Submitted on 4 Mar 2021

HAL is a multi-disciplinary open access archive for the deposit and dissemination of scientific research documents, whether they are published or not. The documents may come from teaching and research institutions in France or abroad, or from public or private research centers.
L'archive ouverte pluridisciplinaire HAL, est destinée au dépôt et à la diffusion de documents scientifiques de niveau recherche, publiés ou non, émanant des établissements d'enseignement et de recherche français ou étrangers, des laboratoires publics ou privés. 
Wavelengths and temporal effects on the response of mammalian cells to UV radiation: limitations of action spectra illustrated by genotoxicity.

\author{
Thierry Douki* \\ Univ. Grenoble Alpes, CEA, CNRS, IRIG, SyMMES, F-38000 Grenoble
}

Corresponding author:

Thierry Douki

Tel: (33) 438783191

Fax: (33) 438785090

Email: thierry.douki@cea.fr

Address:

IRIG/SyMMES UMR 5819, CEA-Grenoble

17 rue des Martyrs 38054

Grenoble Cedex 9

France 


\section{Highlights}

1. Cellular responses to UV are strongly wavelength-dependent

2. Action spectra describe the extent of a response at different wavelengths

3. Non-additive effects may prevent use of action spectra

4. Temporal effects has to be considered when using action spectra

5. New mathematical tools are needed to study the effects of complex UV sources

\section{Graphical Abstract}

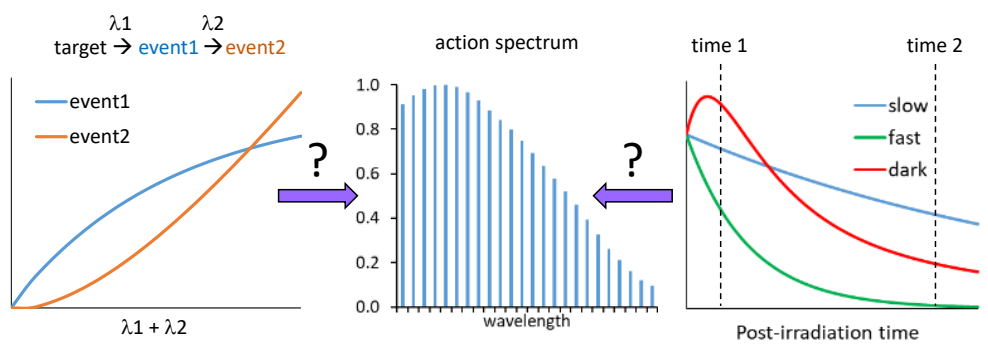




\begin{abstract}
All photobiological events depend on the wavelength of the incident radiation. In real-life situations and in the vast majority of laboratory experiments, exposure always involves sources with various emission spectra spreading over a wide wavelength range. Action spectra are often used to describe the efficiency of a process at different wavelengths and to predict the effects of a given light source by summation of the individual effects at each wavelength. However, a full understanding of the biological effects of complex sources requires more than considering these concomitant events at each specific wavelength. Indeed, photons of different energies may not have additive but synergistic or inhibitory effects on photochemical processes and cellular responses. The evolution of a photobiological response with post-irradiation time must also be considered. These two aspects may represent some limitations to the use of action spectra. The present review, focused on mammalian cells, illustrates the concept of action spectrum and discusses its drawbacks using theoretical considerations and examples taken from the literature. Emphasis is placed on genotoxicity for which wavelength effects have been extensively studied. Other effects of UV exposure are also mentioned.
\end{abstract}

Keywords: wavelength-dependence, skin cancer, action spectra, non-additive effects, models, 


\section{Introduction}

Sunlight exhibits some positive aspects for humans such as the synthesis of vitamin D. However, overexposure to solar UV is at the origin of deleterious processes such as photoaging, impairment of the immune system and skin cancer $[1,2]$. One major aspect to consider in order to understand these biological consequences is the fact that solar UV is constituted of infinity of radiations with wavelengths spreading from 290 to $400 \mathrm{~nm}$, and that biological effects depend on the energy of the incident photons. This spectral distribution varies according to numerous factors such as latitude, altitude, time of the day, etc. $[3,4]$. The intensity the solar UVB $(280-320 \mathrm{~nm})$ radiation reaching the Earth's surface also depends on the content of ozone in the stratosphere [5]. In addition to overexposure to sunlight, increasing use of artificial UV sources of various spectra such as those used in tanning equipment has added new concerns to public health $[6,7]$. The issue of the diversity of UV emission spectra is also important for laboratory experiments since lamps produced by manufacturers have very different features. A major difficulty for photobiologists and photodermatologists is to link the wide variety of biological effects with the numerous UV sources exhibiting different spectra. The most commonly applied strategy is to rely on action spectra, which sum the efficiency of photobiological responses at individual wavelengths. Experimental works and physical considerations have provided guidelines on the proper way to determine these spectra [8-11]. Examples of limitations have been mostly reported for microorganisms and plants. Increasing understanding of the cellular response of mammalian cells and humans to irradiation also shows that combination effects and temporal aspects may hamper the predictive accuracy of action spectra. The purpose of this review is thus to provide an update on these different aspects through theoretical considerations and examples taken from the field of DNA damage for which spectral effects have been widely studied. Reference to other biological effects such as immunosuppression will be also made.

\section{Formation and repair of DNA photodamage, typical wavelength-dependent processes}

Large amounts of information are available for the formation of both direct photoproducts and oxidatively generated lesions in DNA. In addition, works have reported the effects of UVB (280-320 $\mathrm{nm})$ and UVA (320-400 $\mathrm{nm})$ on the DNA repair efficiency. 
The UV portion of electromagnetic radiation is an efficient mutagenic agent [12]. This is mostly explained by the accumulation of DNA damage [13, 14]. Errors occurring upon replication of damaged DNA may lead to mutational events [15] within proto-oncogenes and tumour suppressor genes and thus initiate skin cancer. The yield and nature of UV-induced DNA damage is strongly wavelength dependent. UVB very efficiently induces cyclobutane pyrimidine dimers (CPD) and pyrimidine (6-4) pyrimidone photoproducts (64PP) [16-23]. The yield varies from one photoproduct to the other at the four possible bipyrimidine sequences (TT, TC, CT and CC). TT and TC CPD are the most frequent, and 64PP are roughly 3-times less frequent than CPD [24]. UVA induces CPD [18, 25-32], with a much lower efficiency than UVB, but not 64PP. Another genotoxic effect of UVA is the induction of oxidatively generated DNA lesions (Fig. 1). This occurs through photosensitization processes mediated by endogenous chromophores leading to the formation of reactive oxygen species (ROS) such as radical species and singlet oxygen. A large body of information is available on the formation of 8-oxo-7,8-dihydroguanine (8-oxoGua) and single strand breaks in the DNA of cells exposed to UVA [25, 33-36]. Pyrimidine oxidation products have been shown to be minor products compared to guanine damage $[25,36]$.

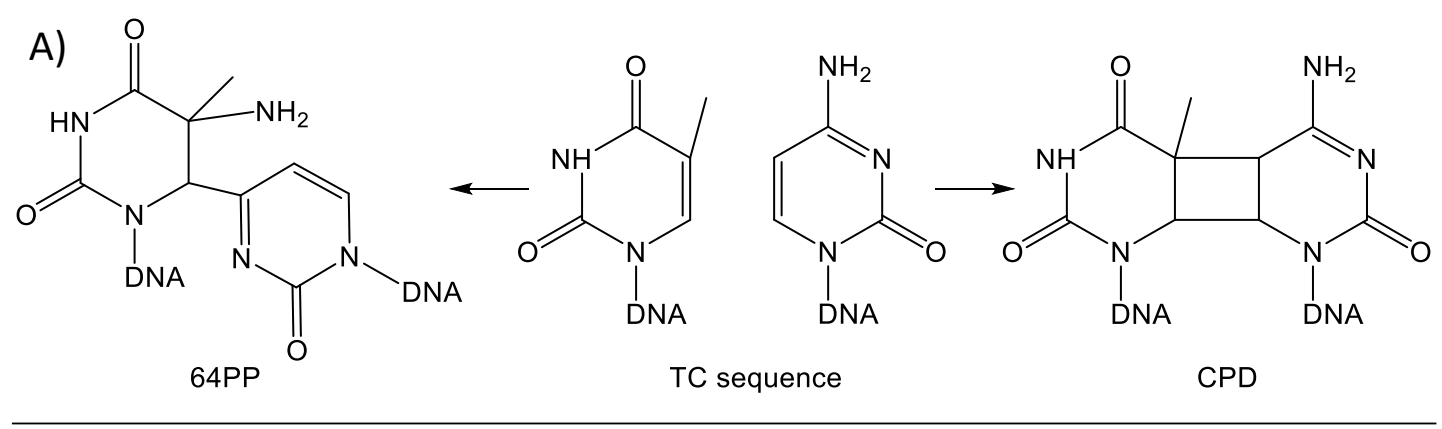<smiles>Nc1nc2c(c(=O)[nH]1)NC(=O)C2=O</smiles><smiles>Nc1nc(NC=O)c(NC(=O)ON(C(F)(F)F)C(F)(F)F)c(=O)[nH]1</smiles><smiles>O=C1NC(=O)N([N+](=O)[O-])C(O)C1O</smiles>

Thy Gly<smiles>O=c1[nH]c(=O)n(O[Na])cc1O</smiles>

Figure 1: Chemical structure of a) pyrimidine dimers (64PP: pyrimidine (6-4) pyrimidone photoproducts, CPD: cyclobutane pyrimidine dimers, $b$ ) various DNA bases oxidation products (8oxoGua: 8-oxo-7,8-dihydroguanine, FapyGua: 2,6-diamino-4-hydroxy-5-formamidopyrimidine),

Thy Gly: thymine glycols, 5-OHCyt: 5-hydroxycytosine) 


\subsection{Modulation of DNA repair by UV radiation}

DNA repair capacities of cells depend on numerous parameters such as the cell type or the cell cycle. In the case of UV effects, the influence of the wavelength must also be taken into account. Repair, which involves mostly nucleotide excision repair (NER) for pyrimidine dimers and base excision repair (BER) for oxidized bases and strand breaks, is modulated by UV. On the one hand, induction of the expression of NER proteins has been shown to increase the repair capacities of cells as the result of exposure to UVB. This is mostly observed upon chronic exposure [37-39] and is explained by overexpression of repair proteins mediated by various factors [40, 41] such as Interleukin-12 [42], E2F1[43], $\alpha-\mathrm{MSH}$ [44], the microRNA MiR-23a [45] or IGF-1 [46]. On the other hand, exposure to UVA leads to a decrease in the rate of repair of pyrimidine dimers induced by a subsequent UVB irradiation, as first observed in keratinocytes [47] and recently extended to melanocytes [48]. This phenomenon could be at least partly explained by the oxidation of DNA repair proteins [49-51]. Other explanations like the modulation of signalling pathways remain to be investigated. It may be added that other aspects of the DNA damage response are differentially modulated by UVB and UVA. Apoptosis has also been shown to be differently induced by different UV ranges [52].

\section{The action spectrum approach}

As illustrated above for DNA damage, the extent of a photobiological response strongly depends on the emission spectrum of the UV source. In order to consider this fact, photobiologists often use action spectra that report the extent of the studied response after monochromatic exposures. The results are usually normalized to the largest value set to 1 . Action spectra are available for numerous processes. In the field of genotoxicity, spectra for the induction of pyrimidine dimers have been determined both in cultured cells [53] and in skin [54]. Other works simultaneously determined action spectra for both pyrimidine dimers and oxidatively generated damage in cultured cells [25, 33]. Action spectra have also been determined for the major UV-induced biological effects including skin cancer in mice [55], erythema [56] and immunosuppression [57]. Action spectra are very useful tools. They can first be used to compare different broadband sources. In this case, the emission spectrum is multiplied by the action spectrum of interest, thereby yielding a "weighted emission spectrum" (Fig. 2). For example, the erythemal weighted emission spectrum is often used to convert physical doses into more biologically relevant units, which are fractions or multiples of erythemal doses. As early as 1974, the spectrum of sunlight weighted for the induction of DNA damage allowed showing the major role of pyrimidine dimers in the induction of skin cancer [58]. The same approach further allowed predicting that UVA is the portion of sunlight playing the most important role in immunosuppression [57]. 

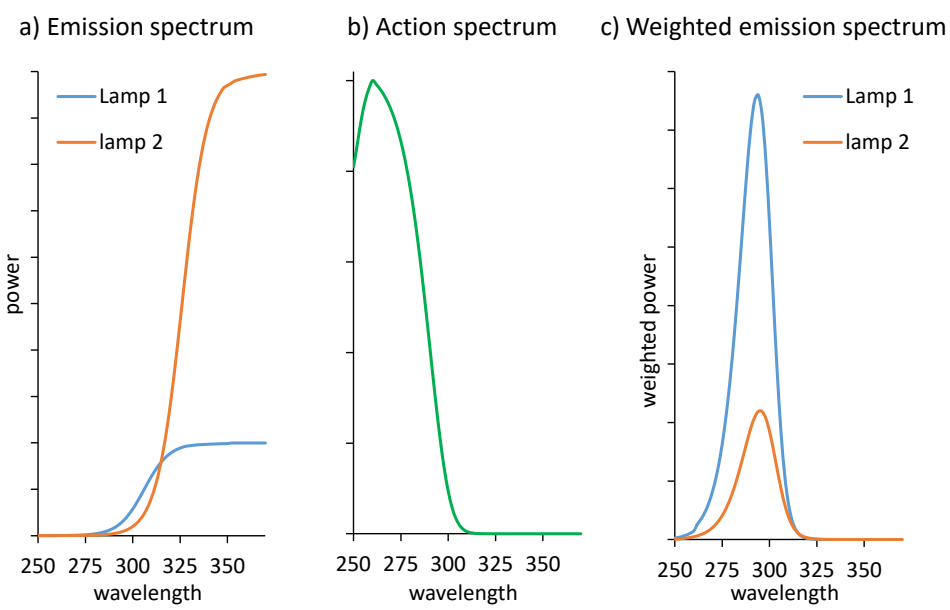

Figure 2: Calculation of weighted emission spectra for the induction of DNA damage. In this example, two lamps are compared, with lamp 1 emitting in both the UVB and UVA ranges being five times less powerful than lamp 2 that emits only UVA radiation. By using the Setlow's action spectrum for induction of CPDs [58], the weighted emission spectra show that lamp 1, richer in wavelengths close to the maximum of the action spectrum, it is actually more efficient than the more intense lamp 2. This illustrates how a minor proportion of UVB in a UVA source can affect biological responses.

A second interest of action spectra is the identification of the cellular chromophores involved in photobiological responses. Indeed, the wavelength corresponding to the maximal amplitude of the studied effect is a clue for to identification of the molecule at the origin of the studied phenomenon. This approach has for example provided major information in the field of photosynthesis. In mammalian cells, a nice example is the work of Coohill and co-workers [59] who used action spectra to show that DNA damage produced by direct absorption was the cause of lethality and mutagenesis induced in the UVB range. Other indirect most likely photosensitized phenomena were involved in the UVA range. The major role played by UVB-induced DNA damage in skin cancer was also supported by the analysis of the action spectrum obtained in a mice study [55]. Interestingly, this action spectrum also showed that skin was strongly protective against high-energy photons with a wavelength below $290 \mathrm{~nm}$. A further illustration of the interest of action spectra in the understanding of photobiological processes is the role of DNA photoproducts in immunosuppression. This link had been suggested by experiments involving topical application of repair enzymes [60] and was reinforced by the observation of a similarity between the wavelength-dependence of the induction of DNA photoproducts and the inflammatory cytokine TNF- $\alpha$ [61]. Similar comparisons of cellular responses and DNA damage formation strongly suggested the involvement of CPD in the induction of erythema [54] and pigmentation [62]. 


\section{Pitfalls in the determination of action spectra}

Determination of accurate action spectra relies on several conditions. A first point is that action spectra must be determined at a dose range where the studied phenomenon is induced in a linear dependence. Figure 3 shows how an action spectrum can be "flattened" when determined in a dose range where the induction of the studied response reaches saturation. Any conclusion made on these bases can thus be misleading since the ratio between the efficiencies of different wavelengths is wrong. This is particularly important in laboratory experiments where high intensity sources can be used. Although biologically relevant doses are rarely high enough to reach such saturation conditions, the issue has been raised for the modelling of the production of vitamin D since some of its metabolites are degraded by overexposure to UVB [63]. It may be stressed that similar considerations should be made for processes induced with a threshold effect or with bell-shaped dose-response curve like immunosuppression [64].
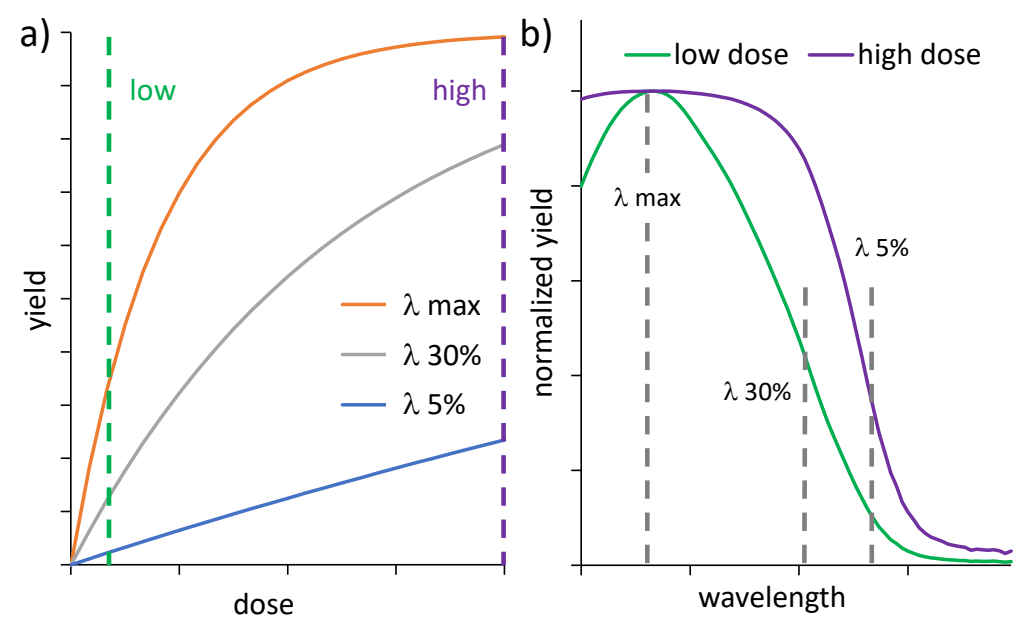

Figure 3: Impact of linearity on the action spectra. a) Yield of a photobiological process is determined at three wavelengths for increasing doses. The wavelengths correspond either to the maximum efficiency or to 30 or $5 \%$ efficiency, respectively. $b$ ) The normalized action spectrum for this response is determined at both low and high doses.

Another point raised is that the studied response should follow the reciprocity rule (Bunsen-Roscoe law). This means that the extent of the studied effect should depend only on the applied dose, irrespectively from the irradiation pattern. Unfortunately, this is not always the case. This has been observed for UVA-induced oxidative stress in human cells [65]. More importantly for human health, a significant effect of the fluence has been reported for the induction of skin cancer, with a higher efficiency at low rates [66, 67]. Similar observations were made for the efficiency of UVB phototherapy [68, 69]. Evidence was also provided for a strong influence of the fluence rate on the induction of oxidative stress in human cells [70]. Similar conclusions were made based on dose 
fractionation experiments [65]. The role of fluence rate has thus to be kept in mind when determining and interpreting action spectra.

\section{Non additive effects}

The main limitation to the action spectrum approach is that it cannot be applied to photobiological processes induced or modulated by consecutive exposure to two (or more) different wavelength ranges. Two main situations can be encountered. The first one is the induction of a photobiological response at a first wavelength followed by a subsequent modulation in a second wavelength range (Fig. 4a). Another possibility is the onset of a response in a portion of the UV spectrum that affects the consequences of the exposure to a second wavelength range (Fig. 4b). In both cases, the correct photobiological consequences cannot be predicted or described by the action spectra because only the effects of individual wavelengths are considered in this approach. Impact of non-additivity on photobiological responses is expected for example in bacteria exposed to sunlight where UVA and visible light-drive repair by photolyases of DNA damage induced by UVB [71, 72]. Examples can also be found in plants. Photomorphogenesis was found to be activated and inhibited at two different wavelengths, which was taken into account in the determination of the action spectra [73]. Another example in plants is the variation in the concentration of various metabolites with respect to UVB to UVA ratio of the light $[74,75]$. The results presented below show that similar phenomena take place in mammalian cells and in humans, in particular regarding DNA damage and oxidative stress.
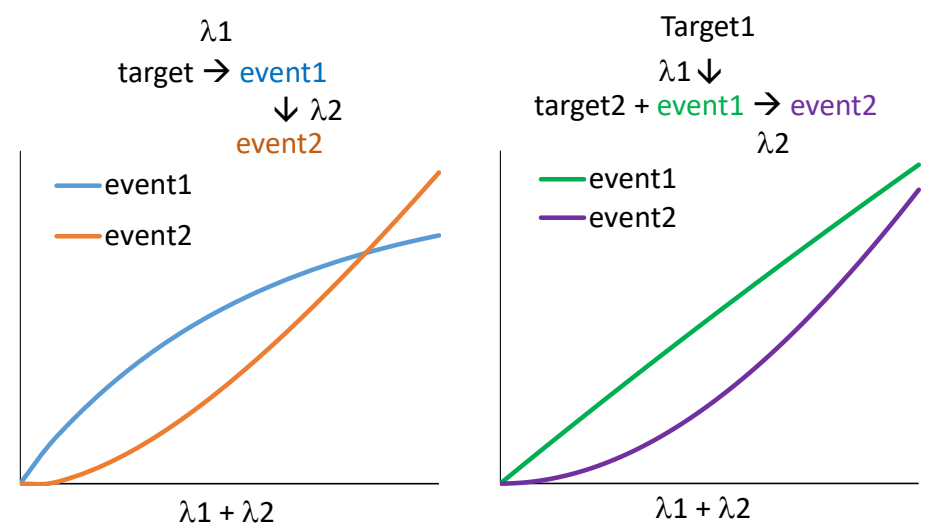

Figure 4: Photobiological processes induced by two wavelengths. A) Photons at a first wavelength $\lambda 1$ hit target 1 and trigger event1. The latter makes possible event 2 under the influence of a second wavelength $\lambda 2$. As the dose increases, event 2 accumulates and event1 reaches a plateau. In the absence of $\lambda 2$, only event 1 takes place. When exposure is limited to $\lambda 2$, nothing happens. B) Action of $\lambda 1$ on target 1 leads to induction of event1. Combined action of event 1 and a second wavelength $\lambda 2$ on target 2 induces event 2 . As the dose increases, the level of event1 increases and induction of 
event 2 is more and more efficient. In the absence of $\lambda 2$, only event 1 is induced while nothing

happens when $\lambda 1$ is missing.

\subsection{Photoisomerisation of 64PP in DNA}

An example of the first case illustrated by figure 4a can be found in the field of genotoxicity. As explained in paragraph 2, 64PP are frequent UVB-induced DNA photoproducts. One of their major chemical properties is their ability to be converted into a Dewar valence isomer (Dewar). Dewar arise from the intramolecular electro-cyclization of the pyrimidone ring of 64PP, which exhibits a strong absorption around $320 \mathrm{~nm}$ [76]. Dewar can be produced by UVB irradiation of pure 64PP in solution. However, the level of Dewar is very low in cells and skin exposed to biologically relevant doses of UVB. As a matter of fact, UVB is absorbed mostly by normal bases and not by the minute amounts of 64PP. Dewar is also basically absent in the DNA of cells exposed to UVA. This UV range does not induce 64PP that necessary precursors for Dewar [18, 30, 77]. A theoretical action spectrum, calculated on the basis of available absorption coefficients and quantum yields, exhibited a maximal yield of Dewar that was 4 orders of magnitude lower than that of CPD and 64PP [78]. This would suggest that Dewar is a very minor DNA lesion. However, Dewar are observed in large amounts when cells and skin are exposed to a combination of UVB and UVA such as natural [79-81] or simulated sunlight $[18,77,82]$. In this case, UVB induces 64PP, which then efficiently absorb UVA photons and undergo photoisomerisation (Fig. 5). Dewar appears thus as an important class of DNA damage to consider [83].<smiles>COn1cc(C)c(=O)[nH]c1=O</smiles><smiles>Cc1cn([N+](=O)[O-])c(=O)nc1N</smiles>

(6-4) photoproduct UVB

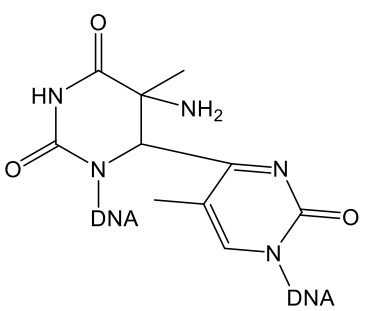

\section{Dewar valence isomer}

UVA

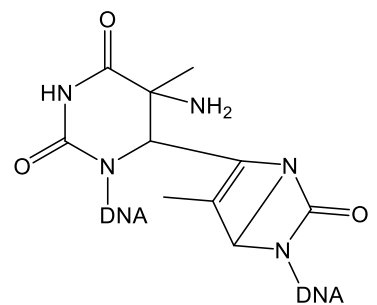

Figure 5: Formation of Dewar valence isomer in DNA upon combined exposure to UVB and

UVA. 64PP is produced in large amounts in the DNA of cells exposed to UVB. Because of the overwhelming presence of normal bases that absorb the vast majority of $U V B$, no photoisomerisation takes place. In contrast, UVA is very weakly absorbed by DNA but more efficiently by 64PP. UVA can thus induce the photoisomerisation of UVB-induced 64PP. It should be stressed that UVA alone does not induce 64PP. 


\subsection{Complex photoreactions leading to oxidative stress}

Photoinduced processes involving photons at two wavelengths may also involve photosensitization reactions. In this case, the dose-dependence is the type described in figure $4 \mathrm{~b}$, with event 1 being the formation of an endogenous photosensitizer. For example, recent results from test tube experiments suggested that DNA damage such as 64PP [84, 85], once formed in DNA, could behave as internal photosensitizers for the formation of CPD or oxidized bases. Although this reaction was found to be poorly efficient [86], it is an example where UVB is required for inducing 64PP and UVA to perform the photosensitization step. The same scheme applies to other biomolecules that can be converted into a photosensitizer in one wavelength range and then induce oxidative stress in another. This is the case of pterin derivatives [87, 88 ] and of some tryptophan photoproducts [89-91]. These compounds are produced by UVB radiation and induce photosensitized-oxidative stress upon exposure to UVA (Fig. 6). Formation of further cellular damage such as the oxidized DNA bases can be anticipated. In a similar way, UVA-induced lipofuscin was reported to photosensitize keratinocytes to visible light [92]. Other combination effects are possible. The recent report of a protective effect of antioxydants against the formation of CPD suggests that UVA-induced oxidized products could behave as DNA sensitizers [93].

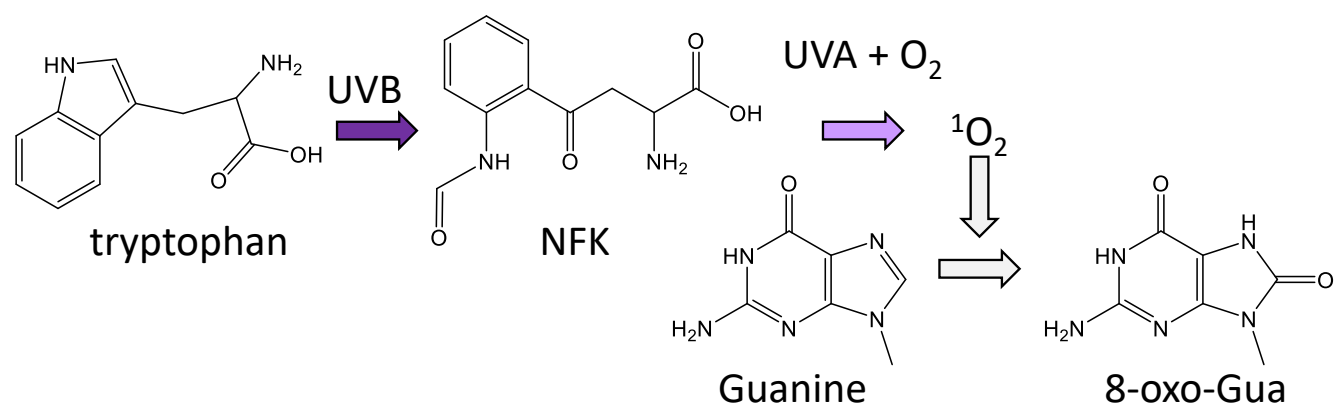

Figure 6: $U V B$-induced formation of a $U V A$-photosensitizer. The represented cascade of events shows the formation of $N$-formylkynurenine (NFK) from tryptophan. NFK can then absorb UVA and produce singlet oxygen, which is at the origin of the formation of 8-oxo-Gua in DNA

\section{Time as a major parameter in predicting photobiological events}

Time plays a major role in the onset of biological effects. Differences are often observed between the temporal evolution of different photobiological responses to UV radiation after exposure. Cascades of events may take place in the minutes and hours after irradiation. Therefore, simultaneous events may not have the same intensity at different times following exposure. Figure 7 illustrates the examples of three different photobiological responses exhibiting different temporal evolution. One decreases rapidly, the other much more slowly while the last one undergoes a phase of "dark induction" after the end of the irradiation. The relative induction of the three studied processes is 
strongly time dependent. Such considerations thus have important consequences in the understanding of biological processes and must be considered when action spectra are used to simultaneously study several endpoints. The importance of these temporal effects is illustrated below for the impact of DNA repair on mutagenesis and the role of photoinduced "dark chemistry" in the induction of cellular damage.

a)

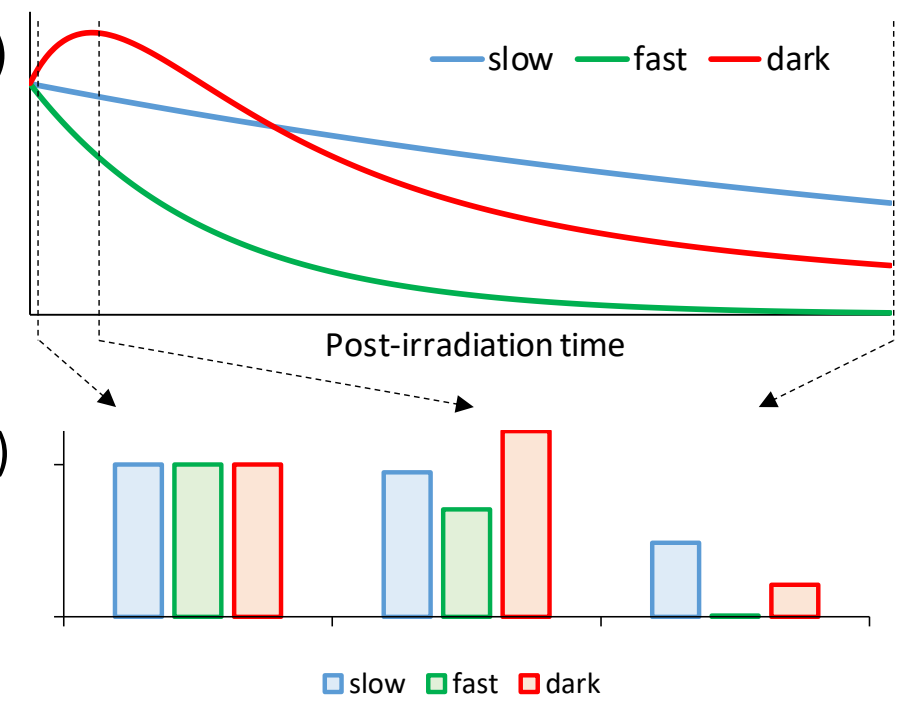

Figure 7: Temporal effects on photobiological responses. Panel a) shows the temporal evolution of three phenomena after irradiation. "Slow" and "Fast" corresponds to responses that decrease with either a slow or a fast rate, respectively. "Dark" corresponds to a process induced during as well as after irradiation and then decreases. (b) The relative inductions of the three processes are no longer the same at different times after irradiation. The reported ratio were calculated immediately after irradiation, at the maximal induction of the "dark process and at the almost complete disappearance of the "fast" response.

\subsection{Mutagenesis and DNA repair}

Unravelling the contribution of the different types of DNA lesions to mutagenesis requires taking into account their respective yield, their intrinsic mutagenic properties and their persistence in the genome. Indeed, only damage present when cells divide can be converted into mutations. A half-division time of $24 \mathrm{~h}$ for keratinocytes in vitro and even longer in skin provides an estimation of the lifetime necessary for a DNA damage to be mutagenic. In terms of mutation, solar mutagenesis has been known for years to be dominated by $\mathrm{C}$ to $\mathrm{T}$ transitions at TC sites and $\mathrm{CC}$ to $\mathrm{TT}$ tandem mutations [15, 94-97]. These results have been strengthened by last generation sequencing techniques applied to thousands of human tumours in order to define specific mutational signatures [98-100]. These mutations arise from the formation of pyrimidine dimers. Experiments involving overexpression of specific repair enzymes showed that mutations induced by UVB result more from CPD than from 
64PP [101, 102]. This could be surprising because in vitro shuttle vector experiments have shown that the intrinsic mutational properties of 64PP are much larger than those of CPD [103-105]. This apparent contradiction can be explained by the difference in the repair rates. 64PP are removed from cells within a few hours by nucleotide excision repair while CPD are still present 24 or $48 \mathrm{~h}$ after irradiation [106-108]. Faster repair of CT CPD compared to TC CPD [109] also explains why mutation at CT are rare events in UV-irradiated cells. In contrast to that of pyrimidine dimers, the signature associated with oxidatively generated damage is rarely encountered in skin cancers, as shown by the absence of the corresponding mutational signature in melanoma [98, 100]. Again, fast repair is a likely explanation to this result, in addition to the fact that oxidized bases and strand breaks are produced with a much lower efficiency than CPD [25, 77]. Because of its efficient repair, the halflife time of 8-oxoGua in cells is in the range of 2-3 hours [110-112]. The repair of single-strand breaks is even faster. Altogether, UV-mutagenesis is a nice example of a situation where action spectra determined immediately after exposure are not relevant. They may yet be useful for the determination of DNA damaging photochemical pathways or for the study of processes where DNA damage is an early sensor.

\subsection{Post-irradiation "dark chemistry"}

The literature also reports that some responses increase not only during but also after irradiation. An example can be found again in the field of DNA damage. CPD were found to be produced within the first few hours following UV irradiation of melanocytes [113]. It was proposed that melanin derivatives were oxidized into endoperoxides that decompose into activated species undergoing energy transfer to DNA bases. Other mechanisms could be involved since similar observations were also made in keratinocytes [93]. In both cell types, involvement of oxidative stress is strongly suggested by the inhibition of this process by antioxidants [93, 113]. Oxidative stress is also possibly induced in a post-irradiation period as shown by the sustained production of reactive oxygen species (ROS) minutes and hours after the end of irradiation [114-116]. Production of ROS can also indirectly induce dark chemistry through the formation of intermediate oxidizing species. One example is the formation of protein peroxides $[117,118]$. It was also reported that peroxidised proteins are able to induce oxidative damage when mixed with DNA [119, 120]. One can thus foresee that oxidized proteins like histones could be the vector of oxidation reactions in the DNA of irradiated cells after the end of the exposure. This possible role of post-irradiation induced oxidative stress is strengthened by the observation of the induction of persistent genomic instability by UVA [121]. 


\section{Combined spectral and temporal effects}

We have seen so far that both non-additive effects of different wavelength bands and temporal effects could limit the accuracy of predictions based on action spectra. Both phenomena may actually take place simultaneously and further complicate the prediction of photobiological responses. A nice illustration is related to DNA repair. As reminded in paragraph 2, UVB and UVA exhibit opposite effects on the efficiency of DNA repair. Therefore, it is expected that the rate of repair of DNA damage will depend on the spectral composition of the incident radiations. UVB-rich sources would accelerate repair while UVA-rich ones would have the opposite effect. Consequently, even if the level of damage is similar immediately after irradiation, the amount of residual damage, which is responsible for mutagenesis, will depend on the UVB to UVA ratio of the source. This effect has been reported for the extent of UV-induced apoptosis that depends on the UVA/UVB ratio [122]. Photoinduced immunosuppression is an even more complicated case. Indeed, it has been shown to be induced faster by UVB than by UVA [123, 124], strongly suggesting a major role of the spectral composition on the extent of the response. It is thus expected that short-term immunosuppression results mostly from UVB while UVA plays a role at longer times. In addition, the immunosuppressive effect of UVB is counteracted by UVA [125, 126]. In this case, both temporal and spectral effects are critically linked and make the use of action spectra almost pointless.

\section{Conclusion}

The above discussion shows that, although powerful tools, action spectra may suffer from limitations associated with possible lack of linearity of the studied response in the considered dose range, nonadditive effects between effects of radiations of different wavelengths, and modulation over time of the response induced immediately after irradiation. In order to avoid misleading conclusions, some guidelines can be proposed:

- When wavelengths effects are not central to an experiment, use of a solar simulator should be preferred to pure UVB or UVA emitting lamps;

- When studies are performed with either UVB or UVA, a control with both wavelength ranges should be included;

- Action spectra should always be determined following exposure to several doses to check the linearity of the induction of the studied response;

- The time-dependence of the response should be studied before determination of an action spectrum.

Most photobiological studies, especially those related to cutaneous and systemic effects, are focused on the UV range of sunlight because of its strong biological impact. Evidence that lower energy 
photons also exhibit biological effects are however accumulating. Infrared light is known for years to have both beneficial and deleterious effects on skin [127-129]. Blue light is also active, as shown by the formation of oxidatively generated DNA bases [33] and more recently by the induction of melanogenesis [130]. A higher level of complexity may combine the impact of circadian rhythm, mostly driven by blue light, with cellular responses such as repair of UVB-induced DNA damage $[131,132]$. The general conclusion of this survey is that novel approaches based on innovative mathematical modelling of biological responses to light are necessary for a better understating and prediction of effects of light on living systems. Interestingly, the field of chemical toxicology provides numerous evidence for the lack of additivity of the biological responses to the components of mixtures, resulting in either synergistic or inhibitory effects [133-140]. Interesting mathematical tools have been developed to provide evidence for non-additivity effects [141]. Photobiology could benefit from using similar approaches.

\section{References}

[1] D. L. Narayanan, R. N. Saladi and J. L. Fox, Ultraviolet radiation and skin cancer, Int. J. Dermatol. 49 (2010) 978-986.

[2] F. R. de Gruijl, H. J. van Kranen and L. H. Mullenders, UV-induced DNA damage, repair, mutations and oncogenic pathways in skin cancer, J. Photochem. Photobiol. B: Biol. 63 (2001) 19-27.

[3] C. Marionnet, C. Tricaud and F. Bernerd, Exposure to Non-Extreme Solar UV Daylight: Spectral Characterization, Effects on Skin and Photoprotection, Int. J. Molec. Sci. 16 (2015) 68-90.

[4] J. E. Frederick, H. E. Snell and E. K. Haywood, Solar ultraviolet-radiation at the Earths surface, Photochem. Photobiol. 50 (1989) 443-450.

[5] R. M. Lucas, M. Norval, R. E. Neale, A. R. Young, F. R. de Gruijl, Y. Takizawa and J. C. van der Leun, The consequences for human health of stratospheric ozone depletion in association with other environmental factors, Photochem. Photobiol. Sci. 14 (2015) 53-87.

[6] P. Autier and J. F. Dore, Ultraviolet radiation and cutaneous melanoma: a historical perspective, Melanoma Res. 30 (2020) 113-125.

[7] D. E. O'Sullivan, T. W. R. Hillier, D. R. Brenner, C. E. Peters and W. D. King, Indoor tanning and the risk of developing non-cutaneous cancers: a systematic review and meta-analysis, Cancer Causes \& Control 29 (2018) 937-950.

[8] L. O. Björn, Action spectroscopy in biology, In Björn, L. O. (Ed.^Eds.), Photobiology: The Science of Light and Life, Springer Science + Business Media, New-York, 2015, pp 85-96.

[9] D. H. Sliney, Photobiological measurements and obtaining action spectra, In Blume, Y., Durzan, D. J. and Smertenko, P. (Ed.^Eds.), Cell Biology and Instrumentation: UV Radiation, Nitric Oxide, and Cell Death in Plants IOS Press, Amsterdam, 2006, pp 11-26.

[10] R. Setlow, Action spectroscopy, Adv. Biol. Med. Phys. 5 (1957) 37-74. 
[11] E. Schäfer and L. Fukshansky, Action spectroscopy, In Smith, H. and Holmes, M. G. (Ed.^Eds.), Techniques in Photomorphogenesis, Academic Press, New-York, 1984.

[12] F. El Ghissassi, R. Baan, K. Straif, Y. Grosse, B. Secretan, V. Bouvard, L. Benbrahim-Tallaa, N. Guha, C. Freeman, L. Galichet and V. Cogliano, A review of human carcinogens-Part D: radiation, Lancet Oncol. 10 (2009) 751-752.

[13] T. Douki, Sunlight-induced DNA damage: molecular mechanisms and photoprotection strategies, In Wondrak, G. T. (Ed.^Eds.), Skin Stress Response Pathways: Environmental Factors and Molecular Opportunities, Springer Int. Publish., 2016, pp 49-77.

[14] J. Cadet and T. Douki, Formation of UV-induced DNA damage contributing to skin cancer development, Photochem. Photobiol. Sci. 12 (2018) 1807-1966.

[15] D. E. Brash, UV signature mutations, Photochem. Photobiol. 91 (2015) 15-26.

[16] S. Y. Wang, Pyrimidine bimolecular photoproducts, (Ed.^Eds.), Photochemistry and Photobiology of Nucleic Acids, Academic Press, New-York, 1976, pp 295-356.

[17] D. L. Mitchell, The induction and repair of lesions produced by the photolysis of (6-4) photoproducts in normal and UV-hypersensitive human cells, Mutat. Res. 194 (1988) 227 237.

[18] D. Perdiz, P. Grof, M. Mezzina, O. Nikaido, E. Moustacchi and E. Sage, Distribution and repair of bipyrimidine photoproducts in solar UV-irradiated mammalian cells. Possible role of Dewar photoproducts in solar mutagenesis, J. Biol. Chem. 275 (2000) 26732-26742.

[19] N. Bastien, J. P. Therrien and R. Drouin, Cytosine containing dipyrimidine sites can be hotspots of cyclobutane pyrimidine dimer formation after UVB exposure, Photochem. Photobiol. Sci. 12 (2013) 1544-1554.

[20] T. Douki and J. Cadet, Individual determination of the yield of the main-UV induced dimeric pyrimidine photoproducts in DNA suggests a high mutagenicity of CC photolesions, Biochemistry 40 (2001) 2495-2501.

[21] S. Adar, J. Hu, J. D. Lieb and A. Sancar, Genome-wide kinetics of DNA excision repair in relation to chromatin state and mutagenesis, Proc. Natl. Acad. Sci. USA 113 (2016) E21242133.

[22] C. A. Chadwick, C. S. Potten, O. Nikaido, T. Matsunaga, C. Proby and A. R. Young, The detection of cyclobutane thymine dimers, (6-4) photolesions and the Dewar valence photoisomers in sections of UV-irradiated human skin using specific antibodies, and the demonstration of depth penetration effects, J. Photochem. Photobiol. B: Biol. 28 (1995) 163170 .

[23] Z. Kuluncsics, D. Perdiz, E. Brulay, B. Muel and E. Sage, Wavelength dependence of ultraviolet-induced DNA damage distribution: involvement of direct or indirect mechanisms and possible artefacts, J. Photochem. Photobiol. B: Biol. 49 (1999) 71-80.

[24] T. Douki, The variety of UV-induced pyrimidine dimeric photoproducts in DNA as shown by chromatographic quantification methods, Photochem. Photobiol. Sci. 12 (2013) 1286-1302.

[25] C. Kielbassa, L. Roza and B. Epe, Wavelength dependence of oxidative DNA damage induced by UV and visible light, Carcinogenesis 18 (1997) 811-816.

[26] P. J. Rochette, J.-P. Therrien, R. Drouin, D. Perdiz, N. Bastien, E. A. Drobetsky and E. Sage, UVA-induced cyclobutane pyrimidine dimers form predominantly at thymine-thymine dipyrimidines and correlate with the mutation spectrum in rodent cells, Nucleic Acids Res. 31 (2003) 2786-2794. 
[27] A. Tewari, M. M. Grage, G. I. Harrison, R. Sarkany and A. R. Young, UVA1 is skin deep: molecular and clinical implications, Photochem. Photobiol. Sci. 12 (2013) 95-103.

[28] A. R. Young, C. S. Potten, O. Nikaido, P. G. Parsons, J. Boenders, J. M. Ramsden and C. A. Chadmick, Human melanocytes and keratinocytes exposed to UVB or UVA in vivo show comparable levels of thymine dimers, J. Invest. Dermatol. 111 (1998) 936-940.

[29] S. Courdavault, C. Baudouin, M. Charveron, A. Favier, J. Cadet and T. Douki, Larger yield of cyclobutane dimers than 8-oxo-7,8-dihydroguanine in the DNA of UVA-irradiated human skin cells, Mutat. Res. 556 (2004) 135-142.

[30] S. Mouret, C. Baudouin, M. Charveron, A. Favier, J. Cadet and T. Douki, Cyclobutane pyrimidine dimers are predominant DNA lesions in whole human skin exposed to UVA radiation, Proc. Natl. Acad. Sci. USA 103 (2006) 13765-13770.

[31] S. Mouret, A. Forestier and T. Douki, The specificity of UVA-induced DNA damage in human melanocytes, Photochem. Photobiol. Sci. 11 (2012) 155-162.

[32] S. Mouret, M. T. Leccia, J. L. Bourrain, T. Douki and J. C. Beani, Individual photosensitivity of human skin and UVA-induced pyrimidine dimers in DNA, J. Invest. Dermatol. 131 (2011) 1539-1546.

[33] E. Kvam and R. M. Tyrrell, Induction of oxidative DNA base damage in human skin cells by UV and near visible radiation, Carcinogenesis 18 (1997) 2379-2384.

[34] B. Cortat, C. C. M. Garcia, A. Quinet, A. P. Schuch, K. M. de Lima-Bessa and C. F. M. Menck, The relative roles of DNA damage induced by UVA irradiation in human cells, Photochem. Photobiol. Sci. 12 (2013) 1483-1495.

[35] C. Kielbassa and B. Epe, DNA damage induced by ultraviolet and visible light and its wavelength dependence, Meth. Enzymol. 319 (2000) 436-445.

[36] J.-P. Pouget, T. Douki, M.-J. Richard and J. Cadet, DNA damage induced in cells by gamma and UVA radiations as measured by HPLC/GC-MS, HPLC-EC and comet assay, Chem. Res. Toxicol. 13 (2000) 541-549.

[37] R. Berube, M. C. Drigeard Desgarnier, T. Douki, A. Lechasseur and P. J. Rochette, Persistence and Tolerance of DNA Damage Induced by Chronic UVB Irradiation of the Human Genome, J. Invest. Dermatol. 138 (2018) 405-412.

[38] M. C. Drigeard Desgarnier, F. Fournier, A. Droit and P. J. Rochette, Influence of a prestimulation with chronic low-dose UVB on stress response mechanisms in human skin fibroblasts, PLoS One 12 (2017) e0173740.

[39] M. C. Drigeard Desgarnier and P. J. Rochette, Enhancement of UVB-induced DNA damage repair after a chronic low-dose UVB pre-stimulation, DNA Repair 63 (2018) 56-62.

[40] H. Chen, Q. Y. Weng and D. E. Fisher, UV signaling pathways within the skin, J. Invest. Dermatol. 134 (2014) 2080-2085.

[41] P. Shah and Y. Y. He, Molecular regulation of UV-induced DNA repair, Photochem. Photobiol. 91 (2015) 254-264.

[42] A. Schwarz, S. Stander, M. Berneburg, M. Bohm, D. Kulms, H. van Steeg, K. GrosseHeitmeyer, J. Krutmann and T. Schwarz, Interleukin-12 suppresses ultraviolet radiationinduced apoptosis by inducing DNA repair, Nature Cell Biol. 4 (2002) 26-31.

[43] T. R. Berton, D. L. Mitchell, R. Guo and D. G. Johnson, Regulation of epidermal apoptosis and DNA repair by E2F1 in response to ultraviolet B radiation, Oncogene 24 (2005) 24492460 . 
[44] L. Dong, J. Wen, E. Pier, X. A. Zhang, B. Zhang, F. Z. Dong, N. Ziegler, M. Mysz, R. Armenta and R. T. Cui, Melanocyte-stimulating hormone directly enhances UV-induced DNA repair in keratinocytes by a xeroderma pigmentosum group A-dependent mechanism, Cancer Res. 70 (2010) 3547-3556.

[45] Z. Guo, B. R. Zhou, W. L. Liu, Y. Xu, D. Wu, Z. Q. Yin, F. Permatasari and D. Luo, MiR23a regulates DNA damage repair and apoptosis in UVB-irradiated HaCaT cells, J. Dermatol. Sci. 69 (2013) 68-76.

[46] M. M. Loesch, A. E. Collier, D. H. Southern, R. E. Ward, S. S. Tholpady, D. A. Lewis, J. B. Travers and D. F. Spandau, Insulin-like growth factor-1 receptor regulates repair of ultraviolet B-induced DNA damage in human keratinocytes in vivo, Molec. Oncol. 10 (2016) 1245-1254.

[47] S. Courdavault, C. Baudouin, M. Charveron, B. Canghilem, A. Favier, J. Cadet and T. Douki, Repair of the three main types of bipyrimidine DNA photoproducts in human keratinocytes exposed to UVB and UVA radiations, DNA Repair 4 (2005) 836-844.

[48] S. Kimeswenger, R. Dingelmaier-Hovorka, D. Foedinger and C. Jantschitsch, UVA1 impairs the repair of UVB-induced DNA damage in normal human melanocytes, Exp. Dermatol. 27 (2018) 276-279.

[49] M. Guven, R. Brem, P. Macpherson, M. Peacock and P. Karran, Oxidative Damage to RPA Limits the Nucleotide Excision Repair Capacity of Human Cells, J. Invest. Dermatol. 135 (2015) 2834-2841.

[50] P. Karran and R. Brem, Protein oxidation, UVA and human DNA repair, DNA Repair 44 (2016) 178-185.

[51] B. Montaner, P. O'Donovan, O. Reelfs, C. M. Perrett, X. Zhang, Y. Z. Xu, X. Ren, P. Macpherson, D. Frith and P. Karran, Reactive oxygen-mediated damage to a human DNA replication and repair protein, EMBO Rep. 8 (2007) 1074-1079.

[52] C. Tuchinda, H. W. Lim, F. M. Strickland, E. A. Guzma' n and H. K. Wong, Comparison of broadband UVB, narrowband UVB, broadband UVA and UVA1 on activation of apoptotic pathways in human peripheral blood mononuclear cells, Photodermatol. Photoimmunol. Photomed. 23 (2007) 2-9.

[53] B. S. Rosenstein and D. L. Mitchell, Action spectra for the induction of pyrimidine(64)pyrimidone photoproducts and cyclobutane pyrimidine dimers in normal human skin fibroblasts, Photochem. Photobiol. 45 (1987) 775-780.

[54] A. R. Young, C. A. Chadwick, G. I. Harrison, O. Nikaido, J. Ramsden and C. S. Potten, The similarity of action spectra for thymine dimers in human epidermis and erythema suggests that DNA is the chromophore for erythema, J. Invest. Dermatol. 111 (1998) 982-988.

[55] F. R. de Gruijl, H. J. Sterenborg, P. D. Forbes, R. E. Davies, C. Cole, G. Kelfkens, H. van Weelden, H. Slaper and J. C. van der Leun, Wavelength dependence of skin cancer induction by ultraviolet irradiation of albino hairless mice, Cancer Res. 53 (1993) 53-60.

[56] A. F. McKinlay and B. L. Diffey, A reference action spectrum for ultraviolet induced erythemal in human skin, CIE Journal 6 (1987) 17-22.

[57] D. L. Damian, Y. J. Matthews, T. A. Phan and G. M. Halliday, An action spectrum for ultraviolet radiation-induced immunosuppression in humans, Br. J. Dermatol. 164 (2011) 657 659.

[58] R. B. Setlow, The wavelengths in sunlight effective in producing skin cancer: a theoretical analysis, Proc. Natl. Acad. Sci. USA 71 (1974) 3363-3366. 
[59] T. P. Coohill, M. J. Peak and J. G. Peak, The effects of the ultraviolet wavelengths of radiation present in sunlight on human cells in vitro, Photochem. Photobiol. 46 (1987) 1043-1050.

[60] M. L. Kripke, P. A. Cox, L. G. Alas and D. B. Yarosh, Pyrimidine dimers in DNA initiate systemic immunosuppression in UV-irradiated mice, Proc. Natl. Acad. Sci. USA 89 (1992) 7516-7520.

[61] S. L. Walker and A. R. Young, An action spectrum (290-320 nm) for TNF alpha protein in human skin in vivo suggests that basal-layer epidermal DNA is the chromophore, Proc. Natl. Acad. Sci. USA 104 (2007) 19051-19054.

[62] N. Agar and A. R. Young, Melanogenesis: a photoprotective response to DNA damage?, Mutat. Res. 571 (2005) 121-132.

[63] A. van Dijk, P. den Outer, H. van Kranen and H. Slaper, The action spectrum for vitamin D3: initial skin reaction and prolonged exposure, Photochem. Photobiol. Sci. 15 (2016) 896909.

[64] Y. J. Matthews, G. M. Halliday, T. A. Phan and D. L. Damian, Wavelength dependency for UVA-induced suppression of recall immunity in humans, J. Dermatol. Sci. 59 (2010) 192197.

[65] H. Merwald, G. Klosner, C. Kokesch, M. Der-Petrossian, H. Honigsmann and F. Trautinger, UVA-induced oxidative damage and cytotoxicity depend on the mode of exposure, J. Photochem. Photobiol. B: Biol. 79 (2005) 197-207.

[66] G. Kelfkens, H. Vanweelden, F. R. Degruijl and J. C. Vanderleun, The influence of dose-rate on ultraviolet tumorigenesis, J. Photochem. Photobiol. B: Biol. 10 (1991) 41-50.

[67] C. C. E. Lan, C. S. Wu, S. M. Huang, C. H. Wu, H. C. Lai, Y. T. Peng, P. S. Hou, H. J. Yang and G. S. Chen, Irradiance-dependent UVB Photocarcinogenesis, Sci. Rep. 6 (2016).

[68] C. C. E. Lan, H. S. Yu, J. H. Lu, C. S. Wu and H. C. Lai, Irradiance, but not fluence, plays a crucial role in UVB-induced immature pigment cell development: new insights for efficient UVB phototherapy, Pigment Cell Melanoma Res. 26 (2013) 367-376.

[69] A. Pacifico, G. Damiani, P. Iacovelli, R. R. Z. Conic, A. Scarabello, A. Filoni, P. Malagoli, N. L. Bragazzi, P. D. M. Pigatto and A. Morrone, Photoadaptation to ultraviolet B TL01 in psoriatic patients, J. Eur. Acad. Dermatol. (2020).

[70] J. D. Hoerter, C. S. Ward, K. D. Bale, A. N. Gizachew, R. Graham, J. Reynolds, M. E. Ward, C. Choi, J. L. Kagabo, M. Sauer, T. Kuipers, T. Hotchkiss, N. Banner, R. A. Chellson, T. Ohaeri, L. Gant and L. Vanderhill, Effect of UVA fluence rate on indicators of oxidative stress in human dermal fibroblasts, Int. J. Biol. Sci. 4 (2008) 63-70.

[71] L. O. Essen and T. Klar, Light-driven DNA repair by photolyases, Cell. Molec. Life Sci. 63 (2006) 1266-1277.

[72] S. Weber, Light-driven enzymatic catalysis of DNA repair: a review of recent biophysical studies on photolyase, Biochim. Biophys. Acta 1707 (2005) 1-23.

[73] R. B. Withrow, W. H. Klein and V. Elstad, Action Spectra of Photomorphogenic Induction and Its Photoinactivation, Plant Physiol. 32 (1957) 453-462.

[74] V. Muller, A. Albert, J. B. Winkler, C. Lankes, G. Noga and M. Hunsche, Ecologically relevant UV-B dose combined with high PAR intensity distinctly affect plant growth and accumulation of secondary metabolites in leaves of Centella asiatica L. Urban, J. Photochem. Photobiol. B: Biol. 127 (2013) 161-169. 
[75] D. Verdaguer, M. A. K. Jansen, L. Llorens, L. O. Morales and S. Neugart, UV-A radiation effects on higher plants: Exploring the known unknown, Plant Sci 255 (2017) 72-81.

[76] J.-S. Taylor and M. P. Cohrs, DNA, light, and Dewar pyrimidones: the structure and biological significance of TpT3, J. Am. Chem. Soc. 109 (1987) 2834-2835.

[77] T. Douki, A. Reynaud-Angelin, J. Cadet and E. Sage, Bipyrimidine photoproducts rather than oxidative lesions are the main type of DNA damage involved in the genotoxic effect of solar UVA radiation, Biochemistry 42 (2003) 9221-9226.

[78] T. Douki, Relative contributions of UVB and UVA to the photoconversion of (6-4) photoproducts into their dewar valence isomers, Photochem. Photobiol. 92 (2016) 587-594.

[79] P. H. Clingen, C. F. Arlett, L. Roza, T. Mori, O. Nikaido and M. H. L. Green, Induction of cyclobutane pyrimidine dimers, pyrimidine(6-4)pyrimidone photoproducts, and Dewar valence isomers by natural sunlight in normal human mononuclear cells, Cancer Res. 55 (1995) 2245-2248.

[80] J. A. Meador, A. J. Baldwin, J. D. Pakulski, W. H. Jeffrey, D. L. Mitchell and T. Douki, The significance of the Dewar valence photoisomer as a UV radiation-induced DNA photoproduct in marine microbial communities, Environm. Microbiol. 16 (2014) 1808-1820.

[81] X. S. Qin, S. M. Zhang, M. Zarkovic, Y. Nakatsuru, S. Shimizu, Y. Yamazaki, H. Oda, O. Nikaido and T. Ishikawa, Detection of ultraviolet photoproducts in mouse skin exposed to natural sunlight, Japan. J. Cancer Res. 87 (1996) 685-690.

[82] D. Bacqueville, T. Douki, L. Duprat, S. Rebelo-Moreira, B. Guiraud, H. Dromigny, V. Perier, S. Bessou-Touya and H. Duplan, A new hair follicle-derived human epidermal model for the evaluation of sunscreen genoprotection, J. Photochem. Photobiol. B: Biol. 151 (2015) 31-38.

[83] T. Douki and E. Sage, Dewar valence isomers, the third type of environmentally relevant DNA photoproducts induced by solar radiation, Photochem. Photobiol. Sci. 15 (2015) 24-30.

[84] V. Vendrell-Criado, G. M. Rodriguez-Muniz, M. C. Cuquerella, V. Lhiaubet-Vallet and M. A. Miranda, Photosensitization of DNA by 5-methyl-2-pyrimidone deoxyribonucleoside: (64) photoproduct as a possible Trojan horse, Angew. Chem. Int. Ed. 52 (2013) 6476-6479.

[85] V. Vendrell-Criado, G. M. Rodriguez-Muniz, V. Lhiaubet-Vallet, M. C. Cuquerella and M. A. Miranda, The (6-4) Dimeric Lesion as a DNA Photosensitizer, ChemPhysChem 17 (2016) 1979-1982.

[86] T. Douki, Pyrimidine (6-4) pyrimidone photoproducts in UVA-irradiated DNA: photosensitization or photoisomerization?, ChemPhotoChem 4 (2020) 294-299.

[87] G. Cremer-Bartels and I. Ebels, Pteridines as nonretinal regulators of light-dependent melatonin biosynthesis, Proc. Natl. Acad. Sci. USA 77 (1980) 2415-2418.

[88] H. Rokos, W. D. Beazley and K. U. Schallreuter, Oxidative stress in vitiligo: photo-oxidation of pterins produces $\mathrm{H}(2) \mathrm{O}(2)$ and pterin-6-carboxylic acid, Biochem. Biophys. Res. Com. 292 (2002) 805-811.

[89] T. M. Dreaden, J. Chen, S. Rexroth and B. A. Barry, N-formylkynurenine as a marker of high light stress in photosynthesis, J. Biol. Chem. 286 (2011) 22632-22641.

[90] S. L. Park, R. Justiniano, J. D. Williams, C. M. Cabello, S. Qiao and G. T. Wondrak, The tryptophan-derived endogenous aryl hydrocarbon receptor ligand 6-formylindolo[3,2b]carbazole is a nanomolar UVA photosensitizer in epidermal keratinocytes, J. Invest. Dermatol. 135 (2015) 1649-1658. 
[91] P. Walrant and R. Santus, N-formyl-kynurenine, a tryptophan photooxidation product, as a photodynamic sensitizer, Photochem. Photobiol. 19 (1974) 411-417.

[92] P. N. Tonolli, O. Chiarelli-Neto, C. Santacruz-Perez, H. C. Junqueira, I. S. Watanabe, F. G. Ravagnani, W. K. Martins and M. S. Baptista, Lipofuscin generated by UVA turns keratinocytes photosensitive to visible light, J. Invest. Dermatol. 137 (2017) 2447-2450.

[93] G. J. Delinasios, M. Karbaschi, M. S. Cooke and A. R. Young, Vitamin E inhibits the UVAI induction of "light" and "dark" cyclobutane pyrimidine dimers, and oxidatively generated DNA damage, in keratinocytes, Sci. Rep. 8 (2018).

[94] D. E. Brash, J. A. Rudolph, J. A. Simon, A. Lin, G. J. McKenna, H. P. Baden, A. J. Halperin and J. Ponten, A role for sunlight in skin cancer: UV-induced p53 mutations in squamous cell carcinoma, Proc. Natl. Acad. Sci. USA 88 (1991) 10124-10128.

[95] N. Dumaz, C. Drougard, A. Sarasin and A. L. Daya-Grosjean, Specific UV-induced mutation spectrum in the p53 gene of skin tumors from DNA-repair-deficient xeroderma pigmentosum patients, Proc. Natl. Acad. Sci. USA 90 (1993) 10529-10533.

[96] N. Dumaz, H. J. van Kranen, A. de Vries, R. J. Berg, P. W. Wester, C. F. van Kreijl, A. Sarasin, L. Daya-Grosjean and F. R. de Gruijl, The role of UV-B light in skin carcinogenesis through the analysis of p53 mutations in squamous cell carcinomas of hairless mice, Carcinogenesis 18 (1997) 897-904.

[97] A. Ziegler, D. J. Leffel, S. Kunala, H. W. Sharma, P. E. Shapiro, A. E. Bale and D. E. Brash, Mutation hotspots due to sunlight in the p53 gene of nonmelanoma skin cancers, Proc. Natl. Acad. Sci. USA 90 (1993) 4216-4220.

[98] L. B. Alexandrov, S. Nik-Zainal, D. C. Wedge, S. A. J. R. Aparicio, S. Behjati, A. V. Biankin, G. R. Bignell, N. Bolli, A. Borg, A. L. Borresen-Dale, S. Boyault, B. Burkhardt, A. P. Butler, C. Caldas, H. R. Davies, C. Desmedt, R. Eils, J. E. Eyfjord, J. A. Foekens, M. Greaves, F. Hosoda, B. Hutter, T. Ilicic, S. Imbeaud, M. Imielinsk, N. Jager, D. T. W. Jones, D. Jones, S. Knappskog, M. Kool, S. R. Lakhani, C. Lopez-Otin, S. Martin, N. C. Munshi, H. Nakamura, P. A. Northcott, M. Pajic, E. Papaemmanuil, A. Paradiso, J. V. Pearson, X. S. Puente, K. Raine, M. Ramakrishna, A. L. Richardson, J. Richter, P. Rosenstiel, M. Schlesner, T. N. Schumacher, P. N. Span, J. W. Teague, Y. Totoki, A. N. J. Tutt, R. Valdes-Mas, M. M. van Buuren, L. van 't Veer, A. Vincent-Salomon, N. Waddell, L. R. Yates, J. Zucman-Rossi, P. A. Futreal, U. McDermott, P. Lichter, M. Meyerson, S. M. Grimmond, R. Siebert, E. Campo, T. Shibata, S. M. Pfister, P. J. Campbell, M. R. Stratton, A. P. C. Genome, I. B. C. Consortium, I. M.-S. Consortium and I. PedBrain, Signatures of mutational processes in human cancer, Nature 500 (2013) 415-421.

[99] C. Consortium, COSMIC, catalog of somatic mutations in cancer, https://cancer.sanger.ac.uk/cosmic/signatures/.

[100] N. K. Hayward, J. S. Wilmott, N. Waddell, P. A. Johansson, M. A. Field, K. Nones, A. M. Patch, H. Kakavand, L. B. Alexandrov, H. Burke, V. Jakrot, S. Kazakoff, O. Holmes, C. Leonard, R. Sabarinathan, L. Mularoni, S. Wood, Q. Y. Xu, N. Waddell, V. Tembe, G. M. Pupo, R. De Paoli-Iseppi, R. E. Vilain, P. Shang, L. M. S. Lau, R. A. Dagg, S. J. Schramm, A. Pritchard, K. Dutton-Regester, F. Newell, A. Fitzgerald, C. A. Shang, S. M. Grimmond, H. A. Pickett, J. Y. Yang, J. R. Stretch, A. Behren, R. F. Kefford, P. Hersey, G. V. Long, J. Cebon, M. Shackleton, A. J. Spillane, R. P. M. Saw, N. Lopez-Bigas, J. V. Pearson, J. F. Thompson, R. A. Scolyer and G. J. Mann, Whole-genome landscapes of major melanoma subtypes, Nature 545 (2017) 175-180. 
[101] J. Jans, W. Schul, Y. G. Sert, Y. Rijksen, H. Rebel, A. P. Eker, S. Nakajima, H. van Steeg, F. R. de Gruijl, A. Yasui, J. H. Hoeijmakers and G. T. van der Horst, Powerful skin cancer protection by a CPD-photolyase transgene, Curr. Biol. 15 (2005) 105-115.

[102] Y. H. You, D. H. Lee, J. H. Yoon, S. Nakajima, A. Yasui and G. P. Pfeifer, Cyclobutane pyrimidine dimers are responsible for the vast majority of mutations induced by UVB irradiation in mammalian cells, J. Biol. Chem. 276 (2001) 44688-44694.

[103] M. J. Horsfall and C. W. Lawrence, Accuracy of replication past the T-C (6-4) adduct, J. Mol. Biol. 235 (1993) 465-471.

[104] J. E. LeClerc, A. Borden and C. W. Lawrence, The thymine-thymine pyrimidine-pyrimidone (6-4) ultraviolet light photoproduct is highly mutagenic and specifically induces 3 ' thymineto-cytosine transitions in Escherichia coli, Proc. Natl. Acad. Sci. USA 88 (1991) 9685-9689.

[105] J.-S. Taylor, Unraveling the molecular pathway from sunlight to skin cancer, Acc. Chem. Res. 27 (1994) 76-82.

[106] J. E. Cleaver, Historical aspects of xeroderma pigmentosum and nucleotide excision repair, Adv. Exp. Med. Biol. 637 (2008) 1-9.

[107] M. Fousteri and L. H. Mullenders, Transcription-coupled nucleotide excision repair in mammalian cells: molecular mechanisms and biological effects, Cell Research 18 (2008) 7384.

[108] D. O. Zharkov, Base excision DNA repair, Cell. Molec. Life Sci. 65 (2008) 1544-1565.

[109] S. Mouret, M. Charveron, A. Favier, J. Cadet and T. Douki, Differential repair of UVBinduced cyclobutane pyrimidine dimers in cultured human skin cells and whole human skin, DNA Repair 7 (2008) 704-712.

[110] A. R. Collins, A. G. Ma and S. J. Duthie, The Kinetics of Repair of Oxidative DNA-Damage (Strand Breaks and Oxidized Pyrimidines) in Human-Cells, Mutat. Res. 336 (1995) 69-77.

[111] A. Klungland, I. Rosewell, S. Hollenbach, E. Larsen, G. Daly, B. Epe, E. Seeberg, T. Lindahl and D. E. Barnes, Accumulation of premutagenic DNA lesions in mice defective in removal of oxidative base damage, Proc. Natl. Acad. Sci. USA 96 (1999) 13300-13305.

[112] W. Eiberger, B. Volkmer, R. Amouroux, C. Dherin, J. P. Radicella and B. Epe, Oxidative stress impairs the repair of oxidative DNA base modifications in human skin fibroblasts and melanoma cells, DNA Repair 7 (2008) 912-921.

[113] S. Premi, S. Wallisch, C. M. Mano, A. B. Weiner, A. Bacchiocchi, K. Wakamatsu, E. J. H. Bechara, R. Halaban, T. Douki and D. E. Brash, Chemiexcitation of melanin derivatives induces DNA photoproducts long after UV exposure, Science 347 (2015) 842-847.

[114] H. Ou-Yang, G. Stamatas, C. Saliou and N. Kollias, A chemiluminescence study of UVAinduced oxidative stress in human skin in vivo, J. Invest. Dermatol. 122 (2004) 1020-1029.

[115] J. Dissemond, L. A. Schneider, M. Wlaschek, T. C. Brauns, M. Goos and K. ScharffetterKochanek, The lazaroid tirilazad is a new inhibitor of direct and indirect UVA-induced lipid peroxidation in human dermal fibroblasts, Arch. Dermatol. Res. 295 (2003) 287-292.

[116] N. C. Moreno, C. C. M. Garcia, V. Munford, C. R. R. Rocha, A. L. Pelegrini, C. Corradi, A. Sarasin and C. F. M. Menck, The key role of UVA-light induced oxidative stress in human Xeroderma Pigmentosum Variant cells, Free Radic. Biol. Med. 131 (2019) 432-442.

[117] M. J. Davies, Protein oxidation and peroxidation, Biochem. J. 473 (2016) 805-825.

[118] D. I. Pattison, A. S. Rahmanto and M. J. Davies, Photo-oxidation of proteins, Photochem. Photobiol. Sci. 11 (2012) 38-53. 
[119] V. I. Bruskov, O. E. Karp, S. A. Garmash, I. N. Shtarkman, A. V. Chernikov and S. V. Gudkov, Prolongation of oxidative stress by long-lived reactive protein species induced by X-ray radiation and their genotoxic action, Free Radic. Res. 46 (2012) 1280-1290.

[120] A. Furukawa, Y. Hiraku, S. Oikawa, C. Luxford, M. J. Davies and S. Kawanishi, Guaninespecific DNA damage induced by gamma-irradiated histone, Biochem. J. 388 (2005) 813818.

[121] R. P. Phillipson, S. E. Tobi, J. A. Morris and T. J. McMillan, UV-A induces persistent genomic instability in human keratinocytes through an oxidative stress mechanism, Free Radic. Biol. Med. 32 (2002) 474-480.

[122] Y. Ibuki, K. M. Dixon and V. E. Reeve, Radiation sources providing increased UVA/UVB ratios attenuate the apoptotic effects of the UVB waveband UVA-dose-dependently in hairless mouse skin, J. Invest. Dermatol. 127 (2007) 2236-2244.

[123] D. L. Damian, R. S. Barnetson and G. M. Halliday, Low-dose UVA and UVB have different time courses for suppression of contact hypersensitivity to a recall antigen in humans, J. Invest. Dermatol. 112 (1999) 939-944.

[124] T. S. C. Poon, R. S. C. Barnetson and G. M. Halliday, Sunlight-induced immunosuppression in humans is initially because of UVB, then UVA, followed by interactive effects, J. Invest. Dermatol. 125 (2005) 840-846.

[125] J. Garssen, F. de Gruijl, D. Mol, A. de Klerk, P. Roholl and H. Van Loveren, UVA exposure affects UVB and cis-urocanic acid-induced systemic suppression of immune responses in Listeria monocytogenes-infected balb/c mice, Photochem. Photobiol. 73 (2001) 432-438.

[126] V. E. Reeve, M. Bosnic, C. Boehm-Wilcox, N. Nishimura and R. D. Ley, Ultraviolet A radiation $(320-400 \mathrm{~nm})$ protects hairless mice from immunosuppression induced by ultraviolet B radiation (280-320 nm) or cis-urocanic acid, Int. Arch. Allergy Immunol. 115 (1998) 316322.

[127] S. Cho, M. H. Shin, Y. K. Kim, J. E. Seo, Y. M. Lee, C. H. Park and J. H. Chung, Effects of Infrared Radiation and Heat on Human Skin Aging in vivo, J. Invest. Derm. Symp. Proc. 14 (2009) 15-19.

[128] L. R. Sklar, F. Almutawa, H. W. Lim and I. Hamzavi, Effects of ultraviolet radiation, visible light, and infrared radiation on erythema and pigmentation: a review, Photochem. Photobiol. Sci. 12 (2013) 54-64.

[129] D. Barolet, F. Christiaens and M. R. Hamblin, Infrared and skin: Friend or foe, J. Photochem. Photobiol. B: Biol. 155 (2016) 78-85.

[130] C. Regazzetti, L. Sormani, D. Debayle, F. Bernerd, G. De Donatis, B. Chignon-Sicard, S. Rocchi and T. Passeron, Melanocytes sense blue-light and regulate the pigmentation through the Opsin 3, J. Invest. Dermatol. 137 (2017) S299-S299.

[131] S. Gaddameedhi, C. P. Selby, W. K. Kaufmann, R. C. Smart and A. Sancar, Control of skin cancer by the circadian rhythm, Proc. Natl. Acad. Sci. USA 108 (2015) 18790-18795.

[132] T.-H. Kang, L. A. Lindsey-Boltz, J. T. Reardon and A. Sancar, Circadian control of XPA and excision repair of cisplatin-DNA damage by cryptochrome and HERC2 ubiquitin ligase, Proc. Natl. Acad. Sci. USA 107 (2010) 4890-4895.

[133] K. L. Harris, J. N. Myers and A. Ramesh, Benzo(a)pyrene modulates fluoranthene-induced cellular responses in HT-29 colon cells in a dual exposure system, Environ.Toxicol. Pharmacol. 36 (2013) 358-367. 
[134] W. K. Lutz, Deviation from additivity in mixture toxicity: Nonlinear dose-response and relevance for genotoxicity, Toxicol. Lett. 189 (2009) S50-S51.

[135] B. Said, M. K. Ross, A. K. Hamade, D. C. Matsumoto and R. C. Shank, DNA-damaging effects of genotoxins in mixture: Nonadditive effects of aflatoxin B-1 and Nacetylaminofluorene on their mutagenicity in Salmonella typhimurium, Toxicol. Sci. 52 (1999) 226-231.

[136] P. A. White, The genotoxicity of priority polycyclic aromatic hydrocarbons in complex mixtures, Mutat. Res. 515 (2002) 85-98.

[137] S. D. Yeatts, C. Gennings, E. D. Wagner, J. E. Simmons and M. J. Plewa, Detecting departure from additivity along a fixed-ratio mixture ray with a piecewise model for dose and interaction thresholds, J. Agri. Biol. Environ. Stat. 15 (2010) 510-522.

[138] C. Genies, A. Jullien, E. Lefebvre, M. Revol, A. Maitre and T. Douki, Inhibition of the formation of benzo a pyrene adducts to DNA in A549 lung cells exposed to mixtures of polycyclic aromatic hydrocarbons, Toxicol. in Vitro 35 (2016) 1-10.

[139] A. Tarantini, A. Maitre, E. Lefebvre, M. Marques, A. Rajhi and T. Douki, Polycyclic aromatic hydrocarbons in binary mixtures modulate the efficiency of benzo[a]pyrene to form DNA adducts in human cells, Toxicology 279 (2011) 36-44.

[140] S. J. Gaskill and E. D. Bruce, Binary mixtures of polycyclic aromatic hydrocarbons display nonadditive mixture interactions in an in vitro liver cell model, Risk Anal. 36 (2016) 968-991.

[141] T. C. Chou, Theoretical basis, experimental design, and computerized simulation of synergism and antagonism in drug-combination studies, Pharmacol. Rev. 58 (2006) 621-281. 